\title{
PETA BARU BISNIS PERBANKAN DI INDONESIA
}

\author{
oleh : \\ Ninik Sri Rahayu *)
}

\begin{tabular}{ll|l}
\hline$\cdot$ ABSTRACT & $\ddots \cdot$ \\
\hline
\end{tabular}

The Indonesian Banking Architecture is a comprehensive, basic framework for the Indonesian banking system. In the Architecture, the policy direction for the future development of the banking industry is based on the vision of building strong and efficient banking system to create financial system stability for the promotion of national economic growth. To bring the vision of the Architecture as described above, the six pillars of the Architecture are designed to ensure the achievement of the architecture vision as follows: healthy banking structure, effective regulatory system, effective and independent supervisory system, strong banking industry, adequate infrastructure, robust customer protection.

The next ten to fifteen years the banking system are expected to move the banking system towards a more optimum structure. This structure is envisaged as follows: two or three banks likely to emerge as international banks, possessing the capacity and ability to operate on an international scale and having total capital exceeding Rp50 trillion, 3 to 5 national banks, having a broad scope of business and operating nationwide with total capital between Rp10 trillion and Rp50 trillion, 30 to 50 banks operating as focused players, with operations focused on particular business segments according to the capability and competence of each bank. These banks will have capital of Rp100 billion up to Rp10 trillion, rural banks and banks with limited scope of business, having capital of less than Rp100 billion.

Key words : Banking architecture, the six pillars of the architecture

Krisis perbankan di Indonesia tergolong paling parah jika dibandingkan dengan krisis serupa yang pernah terjadi di beberapa negara selama ini. Pecahnya gelombang krisis pada tahun 1998 tidak saja memporak-porandakan industri perbankan nasional tetapi juga menyeret perekonomian ke dalam pertumbuhan ekonomi yang begitu lambat. Tidak sedikit bank-bank yang sákit secara finansial tumbang dalam hempasan badai krisis tersebut, bahkan jumlah bank menciut secara signifikan dari sekitar 222 bank di tahun 1998 menjadi 136 di tahun 2004. Salah safu pemicu runtuhnya industri perbankan di Indonesia adälah tingginya tumpukan kredit macet sebagai akibat tidak'diindahkankannya prinsip prudential banking practices oleh para pelaku'bisnis perbankan.

Pada periode -krisis tersebut, pemerintah terpaksa mengetuk pintu IMF (International Monetary Fund) untuk membantu memulihkan perekonomian dari 
jurang kehancuran. Salah satu agenda penting yang direkomendasikan IMF untuk merehabilitasi industri perbankan adalah dengan mendirikan BPPN (Badan Penyehatan Perbankan Nasional) pada tanggal 26 Januari 1998. Lembaga yang lahir sebagai efek krisis ini mengemban tiga tugas pokok yakni pertama, menyehatkan perbankàn. Kedua, menyelesaikan aset-aset perbankan baik berupa aset fisik maupun kewajiban debitur. Ketiga, mengupayakan kembalinya uang negara yang telah disalurkan kepada bank-bank dalam upaya restrukturisasi perbankan. Meski semenjak berdiri sampai kemudian resmi dibubarkan Februari tahun silam banyak menuai kerikil tajam karena tekanan berbagai pihak dan begitu besarnya aset busuk perbankan yang mendekam di tubuh BPPN, harus diakui, lembaga ini relatif berhasil dalam mengentaskan industri perbankan dari keterpurukan. Lima tahun setelah program restrukturisasi yang menelan dana tidak kurang dari 450 trilyun ini berjalan indikator kinerja perbankan mulai menunjukan gejala kearah perbaikan yang cukup berarti.

Laporan BI terakhir menyebutkan bahwa tingkat permodalan bank-bank dalam bentuk CAR pada akhir triwulan 2004 berada pada level yang cukup aman dan stabil yakni berkisar pada angka $21 \%$, jauh diatas CAR standar intemasional sebesar $8 \%$. Sementara itu angka non performing loans (NPLs) net yang mencerminkan beban kredit bermasalah juga berada pada tingkat rendah. Kendatipun angka tersebut belum berada dibawah $5 \%$ tetapi telah menunjukan - pergerakan yang terus menurun dari 35,1\% di masa krisis tahun 1998 menjadi $7,1 \%$. Tidak berbeda dengan indikator lainnya, LDR (Loan to Deposit Ratio) juga memperlihatkan gejala yang terus membaik menuju angka diatas $50 \%$. Perbaikan indikator-indikator perbankan secara detail dapat disimak dalam tabel 1 berikut ini.

Tabel 1

Perkembangan Beberapa Indikator Perbankan 1998-2004

\begin{tabular}{|c|c|c|c|c|c|c|c|c|}
\hline Noy & Ifolkator & 1998 & 19096 & 2000 & 2001 & 2002 & 2003 & 2004 \\
\hline 1. & CAR & $-15,7$ & $-8,7$ & 12,7 & 20,5 & 22,5 & 19,4 & 21,0 \\
\hline 2. & NPL $(\%)$ & 48,6 & 32,8 & 18,8 & 12,1 & 8,1 & 8,2 & 7,1 \\
\hline 3. & LDR (\%) & 72,4 & 26,2 & $\overline{33,2}$ & 33,0 & 38,2 & 48,5 & 55,3 \\
\hline 4. & Total Asset (T RP & 895,5 & $1.006,7$ & $1.030,5$ & $1.099,7$ & $1.112,2$ & 1.196 & 1.208 \\
\hline 5. & NII (T Rp) & $-61,2$ & $-38,5$ & 22,8 & 37,8 & 42,9 & 46,5 & 47,9 \\
\hline
\end{tabular}

Sumber: Bank Indonesia 2004, diolah kembali

Data-data yang terangkum dalam tabel diatas menyajikan cukup bukti bahwa progam restrukturisasi perbankan yang dikomandani BPPN telah berjalan dengan baik, sehingga industri perbankan memiliki pondasi yang lebih kuat dibandingkan dengan lima tahun silam. 
Krisis yang mengoyak industri perbankan tujuh tahun silam meninggalkan luka yang mendalam baik secara sistem, institusi maupun individual. Adalah bukan perkara mudah untuk memulihkan kepercayaan dan kredibilitas dunia perbankan yang mulai membaik seperti sekarang inj. Üntuk. menjaga dan mengamankan sektor perbankan dari kemungkinan terjadinya krisis dikemudian hari, beberapa waktu lalu tepatnya 1 Januari 2004 Bank Indonesia sebagai pemegang otoritas moneter telah meluncurkan sebuah blue print yang dikenal dengan API (Arsitektur Perbankan Indonesia). Sebagai sebuah banking arsitecture, API bertujuan untuk menciptakan perbankan nasional yang sehat, kuat dan mampu menjaga stabilitas sistem keuangan secara keseluruhan serta mampu mendorong pertumbuhan ekonomi nasional. Digulirkannya platform perbankan ini sekaligus memberi harapan akan terwujudnya fundamental perbankan yang kokoh dan mampu mengantisipasi segala bentuk gangguan perbankan baik itu yang bersifat eksternal maupun internal. Jatuhnya industri perbankan di masa krisis, memberi pelajaran berharga bahwa ternyata struktur perbankan di Indonesia masih sedemikian rapuh sehingga tidak berdaya dalam menghadapi ekstemal shock atau gelombang yang datang secara tiba-tiba seperti yang terjadi pada pertengahan 1997 silam.

Sebagai sebuah konsep, dapat dikatakan API merupakan konsep yang bersifat komprehensif dan utuh karena didalamnya memuat selukbeluk kehidupan perbankan dari A sampai Z, mulai dari kelembagaan, struktur, pengawasan dan lembaga penunjang lainnya. Dengan demikian, API ini tidak saja merupakan policy guidance tapi sekaligus sebagai policy recommendation yang memberikan kejelasan arah, tujuan dan tatanan perbankan nasional dalam rentang $10-15$ tahun mendatang. Secara bertahap Bank Indonesia mulai memberlakukan implementasi API semenjak tahun 2004. Apabila pada periode 1998-2004 dunia perbankan menjalani tahap penyehatan secara finansial melalui BPPN, maka dengan hadimya API perbankan memasuki tahap baru berupa penyehatan operasional. Tahap-tahap implementasi API tersebut terangkum dalam tabel 2 berikut ini : 
Tabel 2

Tahap-Tahap Implementasi API

\begin{tabular}{|c|c|}
\hline A. Program Penguatan Struktur Perbankan Nasional (Pikar) & $\begin{array}{l}\text { Periode } \\
\text { Pelaksanaan }\end{array}$ \\
\hline $\begin{array}{l}\text { 1. Memperkuat permodalan bank } \\
\text { a. Meningkatkan persyaratan minimum bagi bank umum (termasuk BPD) } \\
\text { menjadi Rp.100 Milyar } \\
\text { b. Mempertahankan persyaratan modal Rp.3 trilyun untuk pendirian bank } \\
\text { baru sampai dengan } 1 \text { Januari } 2011 \\
\text { 2. Memperkuat daya saing B PR } \\
\text { a. Meningkatkan linkage program antara bank umum dan BPR } \\
\text { b. Mempermudah pembukaan kantor cabang BPR } \\
\text { c. Memfasilitasi pembentukan fasilitas jasa bersama untuk BPR } \\
\text { 3. Meningkatkan akses kredit } \\
\text { a. Memfasilitasi pembentukan skim penjamin kredit } \\
\text { b. Mendorong penyaluran kredit untuk sector usaha tertentu. }\end{array}$ & $\begin{array}{l}2004-2010 \\
2004-2010 \\
2004 \\
2004 \\
2004-2005 \\
2004-2006 \\
2004-2006\end{array}$ \\
\hline B. Program Peningkatan Kualitas Pengaturan Perbankan (Pilar II) & $\begin{array}{l}\text { Periode } \\
\text { Pelaksanaan }\end{array}$ \\
\hline $\begin{array}{l}\text { 1. Mem formalkan proses sindikasi dalam membuat kebijakan perbankan. } \\
\text { a. Melibatkan pihak ketiga dalam setiap pembuatan kebijakan perbankan } \\
\text { b. Membentuk panel ahli perbankan } \\
\text { c. Memfasilitasi pembentukan lembaga riset perbankan di daerah ataupun } \\
\text { 2. Implementasi secara bertahap } 25 \text { Basel Core Principles For Effective Banking } \\
\text { Supervision. }\end{array}$ & $\begin{array}{l}2004 \\
2004 \\
2004-2005 \\
2004-2013\end{array}$ \\
\hline C. Program Peningkatan Fungsi Pengawasan & $\begin{array}{l}\text { iode } \\
\text { sanaan }\end{array}$ \\
\hline $\begin{array}{l}\text { 1. Meningkatakan koordinasi antar lembaga pengawas } \\
\text { a. Melakukan koordinasi dan kerjasama secara regular } \\
\text { 2. Mengkonsolidasikan sektor perbankan Bank Indonesia } \\
\text { a. Mengonsolidasi fungsi pengawasan dan pemerisaan } \\
\text { b. Mereorganisasi sektor perbankan Bank Indonesia } \\
\text { c. Membentuk tim enforcement. } \\
\text { d. Membentuk tim khusus pemeriksa spesialis } \\
\text { 3. Meningkatkan.kompetensi pemeriksa bank } \\
\text { a. Melakukan sertifikasi pemeriksa bank } \\
\text { b. Melakukan attachment pemeriksa di lembaga pengawas internasional } \\
\text { 4. Mengembangkan system pengawasan berbasis resiko } \\
\text { a. Mendesain risk based model untuk pengawasan } \\
\text { 5. Meningkatkan efektifitas Enforcement } \\
\text { a. Menyempurnakan proses investigasi kejahatan perbankan } \\
\text { b. Meningkatakan transparasi pengawasan dan enforcement } \\
\text { c. Membentuk internal ombudsman untuk permasalahan pengawasan } \\
\text { d. Meningkatakan perlindungan hokum bagi pengawas bank }\end{array}$ & $\begin{array}{l}2004 \\
2004-2005 \\
2004-2005 \\
2004-2005 \\
2004-2005 \\
2004-2005 \\
2004-2005 \\
2004-2005 \\
2004-2005 \\
2004-2005 \\
2004-2005 \\
2004\end{array}$ \\
\hline $\begin{array}{l}\text { D. Program Peningkatan kualitas Manajemen dan Operasional Perbankan (Piar } \\
\text { IV) }\end{array}$ & $\begin{array}{l}\text { ode } \\
\text { anaan: }\end{array}$ \\
\hline $\begin{array}{r}\text { 1. Meningk } \\
\text { a. } \mathrm{Me} \\
\text { b. } \mathrm{Me} \\
\text { 2. Meningk }\end{array}$ & 2004-2005 \\
\hline
\end{tabular}

.. Sumber : Infobank edisi Februari $2004^{\circ}$ 
Program Penguatan Struktur Perbankan Nasional

Langkah yang di ayun Bank Indonesia untuk menempatkan penguatan struktur perbankan nasional sebagai pilar pertama dalam program API merupakan kebijakan stategis dalam rangka menciptakan sistem perbankan nasional tangguh di masa depan. Dalam pilar pertama ini, struktur perbankan dikotak-kotakan berdasar size modalnya sebagaimana tercermin dalam gambar 1 berikut ini :

\section{Gambar 1}

Struktur Perbankan Nasional Berdasarar API

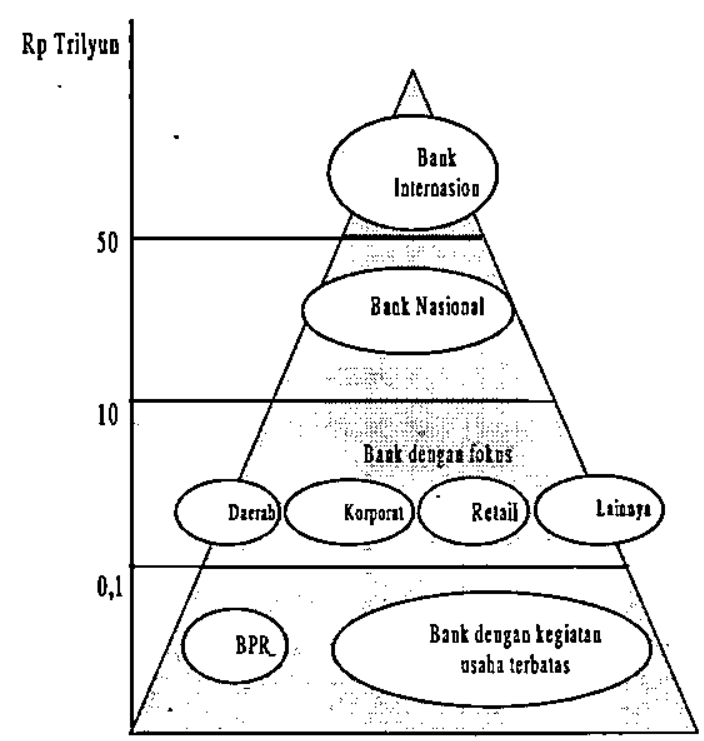

Sumber: Bank Indonesia 2004

Gambar.1 memperlihatkan dengan jelas bahwa regulasi API akan menjadikan pasar perbankan nasional tersegmentasi berdasarkan besarnya modal yang dimiliki oleh tiap-tiap bank. Terhitung mulai tahun 2011 mendatang bank yang memiliki kisaran modal diatas 50 trilyun akan mendapat predikat sebagai bank kelas internasional dan berhak membuka cabang di luar negeri, bank-bank ini nantinya akan bersaing dengan Maybank milik Malaysia ataupun DBS di Singapura. Selanjutnya, bagi bank dengan modal antara 10-50 trilyun akan menjadi bank kelas nasional yang bisa membuka cabang di seluruh provinsi. Dan untuk bank yang mengantongi modal 100 milyar sampai dengan 10 , trilyun akan berada dalam kelas sebagai bank dengan usaha tertentu (bank fokus). Bank dapat dikatakan sebagai sebagai bank fokus apabila $80 \%$ kredit yang dikucurkan bergerak di sektor usaha tertentu, apabila sẹbuah bank menyalurkan $80 \%$ 
kreditnya di sektor retail maka bank tersebut akan menjadi bank retail atau jika bank mengalokasikan $80 \%$ kreditnya ke sektor corporate maka akan disebut sebagai bank corporate. Sementara itu, pada strata terbawah dalam konsep API akan ditempati oleh bank-bank dengan struktur modal kurang dari 100 milyar, $\mathrm{BI}$ menyebut kelompok ini sebagai rural banking atau BPR.

Bank Indonesia sebagai otoritas pengawas perbankan nasional melalui pilar pertama API merekomendasikan bank umum (baik konvensional maupun syariah) agar memiliki modal minimum sebesar Rp100 miliar selambat-lambatnya sampai akhir tahun 2010, sehingga pada tanggal 1 Januari 2011 semua bank umum yang beroperasi sudah memenuhi ketentuan modal minimum yang ditetapkan BI. Keputusan BI untuk memperketat persoalan modal ini sangat wajar dan logis mengingat industri perbankan adalah jenis industri yang bersifat capital intensive sehingga harus memiliki modal yang kuat agar mampu mengcover risiko-resiko yang mungkin dihadapi dalam proses operasinya. Lebih dari itu, kebijakan ini didasarkan pada pertimbangan-pertimbngan rasional seperti rendahnya kinerja bank bermodal dibawah 100 milyar, persoalan pertumbuhan ekonomi, prudentcial banking practices, best practice dan studi empiris. Dibawah ini adalah uraian yang dapat memberikan justifikasi terhadap kebijakan $\mathrm{Bl}$ dalam mengatur dan mengawasi aspek permodalan bank:

1. Kinerja bank dengan modal dibawah 100 milyar

Bank Indonesia menyebutkan saat ini terdapat 55 Bank yang memiliki modal dibawah Rp100 milyar atau sekitar $40 \%$ dari 134 bank yang ada. Total aset bank-bank tersebut hanya sekitar Rp24,5 triliun atau 2,2\% dari seluruh aset perbankan nasional. Sementara itu, aktifitas penyaluran kredit dari ke 55 bank tersebut memiliki porsi yang sangat rendah yakni $2,8 \%$ dari keseluruhan kredit yang disalurkan oleh perbankan. Selain itu, jika dilihat dari sisi efisiensi yang diukur dengan cara membandingkan biaya operasional dan pendapatan operasional (BOPO) menunjukan rasio BOPO sebesar136,8\%. Dengan rasio BOPO diatas $100 \%$ tersebut mengindikasikan bahwa seluruh pendapatan operasional yang diperoleh bank termakan habis untuk membiayai operasional bank. Hal ini bertolak belakang dengan rasio BOPO untuk industri perbankan nasional telah mencapai $91,5 \%$, sehingga lebih efisien dibandingkan dengan bank-bank yang memiliki modal kecil (Sugiharto, 2004). Dengan menyimak kondisi riil yang terjadi pada ke 55 bank tersebut, maka sudah sewajarnya apabila bank-bank kecil yang memiliki permodalan dibawah Rp100 miliar diharuskan untuk meningkatkan kemampuan kapitalnya. Peningkatan kemampuan tersebut bukan hanya untuk memperbesar tingkat profitabilitas melainkan juga untuk memperbaiki efisiensi usahanya.

2. Pertumbuhan ekonomi

Salah satu visi yang dibangun API adalah menciptakan perbankan nasinonal yang sehat sehingga mampu mendorong pertumbuhan ekonomi yang berkelanjutan melalui fungsi intermediasi perbankan. Untuk mendorong pertumbuhan ekonomi nasional sebesar $5 \%-6 \%$ dukungan kredit perbankan yang diperlukan adalah sebesar $22 \%$ setiap tahunnya (ibit :2004). Artinya, 
untuk mencapai target pertumbuhan kredit sebesar $22 \%$ mutlak diperlukan adanya suntikan modal yang lebih besar karena potensi kredit perbankan saat ini hanya sebesar $16 \%$. Penambahan modal ini nantinya akan sangat membantu peningkatan kapasitas lending perbankan kepada pihak ketiga.

3. Persyaratan kehati-hatian

Modal dapat diibaratkan sebagai engine bagi kegiatan bank, rendahnya kapasitas permodalan bank akan berimplikasi serius terhadap kemampuannya dalam mengatasi dan mensiasati kompleksitas resiko perbankan baik itu resiko operasional maupun resiko finansial. Lebih dari itu, sempitnya modal yang dimiliki bank akan menyebabkan level kegiatan usaha bank (level of playing field) menjadi tidak leluasa. Dengan demikian, modal minimal 100 milyar merupakan sebuah keharusan agar bank dapat beroperasi secara lebih. baik.

4. Best practice

Jika dibandingkan dengan negara-negara tetangga di kawasan Asean, sebenarnya persyaratan modal minimum Rp100 miliar'yang ditetapkan di dalam API tersebut sebenarnya masih relatif kecil. Malaysia menerapkan persyaratan modal minimum sebesar Rp 4 triliun, Singapura Rp7 triliun dan Korea sekitar 700 miliar. Jelas sekali bahwa angka-angka yang ditetapkan oleh bank-bank di negara tetangga tersebut jauh lebih besar dibandingkan yang direkomendasikan BI melalui API. Untuk mewujudkan struktur perbankan yang kuat, maka perbankan Indonesia perlu mejadikan best practice di negaranegara yang sistem perbankan sudah mapan sebagai suatu acuan.

5. Studi empiris

API menjadi kebutuhan mendesak bagi industri perbankan nasional dalam kerangka membangun struktur perbankan yang lebih optimal di masa mendatang. Persyaratan modal minimal yang ditetapkan Bl bukannya lahir tanpa sebuah alasan, Ratnawati (2004) menegaskan bahwa bank dapat beroperasi secara efisien apabila total aset yang dimiliki berada dalam kisaran US $\$ 2$ milyar sampai 10 US $\$$ milyar atau sekitar 100 trilyuṇ. Namun demikian, hal ini tentu saja belum dapat diberlakukan di Indonesia mengingat dunia perbankan baru saja pulih dari krisis. Jadi, penetapan modal minimal 100 milyar tersebut sebenarnya sudah cukup realitis dengan tidak hanya mempersoalkan faktor kemampuan bank dalam memenuhi persyaratan yang telah digariskan tetapi juga dengan melihat potensi pertumbuhan perbankan dalam jangka panjang.

Untuk memenuhi ketentuan API, bank-bank yang masih bermodal kurang dari 100 milyar harus segera menyusun business plan yang memuat langkah dan strategi untuk mencapai modal minimal 100 milyar dalam kurun waktu 6 tahun mendatang. Sebab, apabila persyaratan ini tidak terpenuhi bank harus siap untuk tersingkir dan turun pada kelas terendah dan ákan menjadi Bank Perkreditan Rakyat (BPR). Silalahi (2004) menjelaskan, bagi bank-bank yang masih bermodal tipis dapat memupuk permodalannya melalui beberapa cara 
diantaranya, pertama, penambahan modal baru baik dari shareholderlama bank maupun investor baru. Kedua, penggabungan usaha (merger) dengan beberapa bank. Ketiga, dengan secondary offering di pasar modal (Go-Public) sehingga bank akan mampu meningkatkan permodalannya. Keempat, penerbitan pinjaman subordinasi yang dapat dimasukan dalam perhitungan modal bank.

Selain menyoal permasalan kapital, kebijakan BI yang tertuang dalam pilar pertama API secara eksplisit juga telah menegaskan bahwa untuk mewujudkan struktur perbankan yang sehat tidak hanya dibangun melalui. penguatan aspek permodalan bank-bank umum saja namun juga harus meningkatkan peran serta BPR dalam peta perbankan nasional untuk melayani lapisan masyarakat yang tidak terjamah oleh pelayanan bank umum. Kendatipun BPR berada dalam lapisan paling bawah dalam struktur perbankan, bukan berarti $\mathrm{BI}$ tidak memikirkan kelangsungan hidup BPR. Tabel 1 menginformasikan dengan rinci bahwa untuk memperkuat lapisan terbawah dalam struktur API BI menyiapkan tiga strategi yaitu melalui peningkatkan linkage program antara bank umum dan BPR, mempermudah pembukaan kantor cabang BPR dan memfasilitasi pembentukan fasilitas jasa bersama untuk BPR.

\section{B.1 Pengaturan Perbankan Yang Efektif}

Untuk menciptakan perbankan yang sehat dan kuat dalam jangka panjang harus diikuti dengan sistem pengaturan perbankan yang efektif. Sejalan dengan pemikiran tersebut dalam pilar kedua API (tabel 1) disébutkan bahwa untuk memperbaiki proses penyusunan dan ketentuan perbankan maka pihak ketiga dapat terlibat dalam setiap pembuatan kebijakan perbankan untuk menjamin transparasi dan akuntabilitasnya dihadapan publik. Disamping itu, pengaturan perbankan yang efektif juga dapat didorong melalui pembentukan panel ahli perbankan dan pembentukan lembaga riset perbankan di daerah ataupun pusat.

\section{B.2 Pengawasan Bank Yang Independen dan Efektif}

Bisnis perbankan adalah bisnis dalam belantara resiko. Kompleksitas resiko yang menghadang bisnis ini harus diimbangi dengan pengawasan yang independen dan efektif sebagaimana terakomodir dalam pilar ketiga API. Dewasa ini perkembangan bisnis perbankan bergerak sedemikian cepat terutama dalam hal perkembangan produk. Bank kini tidak hanya berhenti untuk menawarkan produk-produk tradisional seperti tabungan, deposito ataupun giro namun telah merambah pada produk-produk keuangan lain seperti asuransi dan reksadana. Inovasi produk-produk perbankan itu sendiri merupakan tuntutan pasar yang tidak bisa dihindari sebab sekarang ini nasabah sudah begitu banking minded sehingga menginginkan seluruh pelayanan keuangan yang mereka butuhkan berada dalam satu atap. Perkembangan bank yang mengarah pada financial supermarkèt ini tentu saja mengundang resiko yang tidak sedikit. Untuk menjawab tingginya resiko ini $\mathrm{BI}$ mengembangkan sistem pengawasan bank yang berbasis pada resiko (risk based model) sebagaimana tercermin dalam pilar ketiga API. 
B.3 Kualitas Manajemen dan Operasional Perbankan .

Dalam upaya meningkatan kualitas menajemen perbankan, BI mengádopsi prinsip-prinsip tata kelola yang baik atau lebih dikenal dengan good corporate governance (GCG) sebagai basis penguatan intemal perbankan sebagaimana tergambar dalam pilar keempat API. Kebijakan Bl untuk memberlakukan standar minimal $G C G$ ini merupakan langkah urgen yang sudah selayaknya ditempuh, sebab, sejarah hitam yang ditorehkan perbankan pada episode krisis tujuh tahun silam tidak lepas;dari diabaikannya praktek-praktek GCG. Selain menetapkan standar minimum,GCG, BI juga mendorong bank-bank untuk go publik. Dengan menjadi bank go-publik maka persyaratan transparansi dan kontrol pengendalian masyarakat menjadi semakin beșar, sehingga kasus-kasus pembobolan bank maupun improver behavior liainnyá dapăt diminimalkan.

Upaya peñcegahan tèrjadinya moral hazard yang merupakan salah satu bentuk resiko operasional dalam dunia perbankan diantisipasi $\mathrm{Bl}$. dengan. mensyaratkan adanya sertifikasi untuk para risk manager. Penutupan Bank Dagang Bali dan Bank Asiatic pada akhir tahun 2004 yang lalu memberikan sinyal bahwa tidak semua manajemen bank memiliki keahlian dan kompetensi yang memadai untuk mengelola segala bentuk resiko yang menghantui bisnis ini baik yang menyangkut sistem, prosedur maupun sumber daya manusia., Dengan adanya program sertifikasi memungkinkan semua risk manager dalam industri perbankan memiliki standar kualitas minimum dalam hal keahlian; kompetensi dan pengetahuan tentang manajemen resiko sehingga potensi kenugian yang mungkin diderita oleh suatu bank dapat ditekan serendah mungkin. BI berharap dengan adanya program sertifikasi yang di dalam konsep API mulai diberlakukan tahun ini akan mendorong terciptanya internal control system yang bersifat build-in karena manajemen bank telah memiliki risk manajer yang kompeten dalam mengelola resiko-resiko yang mungkin dihadapi.

\section{B.4 Infrastruktur Pendukung}

BI menggagas tersedianya biro kredit (credit bureau) sebagai infrastruktur pendukung untuk mempercepat proses pemberian kredit kepada para debitur atau pihak ketiga. Gagasan yang termaktup dalam pilar kelima API ini mengacu pada supporting infrastructure perbankan di negara-negara maju dimana dalam konsep biro kredit ini memungkinkan tersedianya data historis mengenai kondisi keụangan calon debitur. Konsekuensi logis dari penerapan perangkat pendukung ini adalah terekamnya tract record seorang calon debitur, sehingga apabila si calon debitur yang bersangkutan pemah bermasalah dengan pihak bank dalam hal kredit dengan sendirinya akan masuk dalam daftar hitam (black list) perbankan.

\section{B.5 Perlindungan konsumen}

Salah satu agenda besar dan menjadi tantangan Bl saat ini adalah bagaimana menciptakan sebuah mekanisme yang mengatur pengaduan nasabah yang tengah bermasalah dengan pihak bank. Indonesia terhitung sebagai negara 
yang tertinggal dalam hal perlindungan nasabah. Dalam banyak kasus, nasabah kerap berada dalam posisi yang lemah dan tidak jarang menjadi pihak yang dirugikan. Dimasukkannya program perlindungan nasabah dalam pilar keenam API ini sekaligus mengindikasikan bàhwa BI memiliki itikad baik untuk menempatkan posisi nasabah setara dengan pihak bank Dalam pilar terakhir ini selain mengatur standar mekanisme pengaduan nasabah, Bl.juga beinisiatif untuk membentuk lembaga mediasi independen yàng menjadi jembatan antara nasabah dan bank. Transparasi informasi produk dan edukasi terhadap konsumen juga tidak luput dari perhatian $\mathrm{Bl}$, dalam program perlindungan nasabah ini konsumen berhak untuk mendapatkan penjelaskan mengenai keuntungan, resiko dan prospek prodük-prodükyang ditawarkan oleh bank. Alasan yang lebih subtantif dari program perlindungan nasabah ini adalah untuk menumbuhkan kembali kepercayaan nasabah terhadap dunia perbankan yang sempat tercerabut akibat penutupan 16 bank oleh pemerintah beberapa tahun lalu. Kepercayaan nasabah sesungguhnya merupakan sebuah elemen abstrak namun șangat fundamental bagi kehidupan perbankan, oleh sebab itu adalah masuk akal apabila $\mathrm{BI}$ berkepentingan untuk mewujudkan program ini dalam salah śatu pilar API.

c.

C.

Dalam sistem ketatanegaraan, Arsitektur Perbankan Indonesia dapat diumpamakan sebagai Garis-Garis Besar Haluan Negará (GBHN). Dimana didalamnya terdapat garis-garis rencana jangka panjang'perbankan selama rentang waktu 5-10 tahun mendatang. Dalam rentang waktu tersebut BI berharap perbankan Indonesia akan terdiri dari 2-3 bank berkelas internasional (international champions) dengan kapasitas dan kemampuan untuk beroperasi di wilayah internasional serta memiliki modal di atas $\mathrm{Rp} 50$ triliun, $\widehat{3}-\overline{5}$ bank nasional (national champions) yang memiliki cakupan usaha yang sangat luas dan beroperasi secara nasional serta memiliki modal antara $R p 10$ triliun sampai dengan $R p 50$ triliun, 30-50 bank spesialis yang kegiatan usahanya terfokus pada segmen usaha tertentu sesuai dengan kemampuan dan kompetensi masing-masing bank. Bankbank tersebut memiliki modal antara Rp 100 miliar sampäi dengan Rp 10 triliun dan berfokus pada segmen daerah, koperasi, ritel, dan lainnya. Struktur lainnya adalah Bank Perkreditan Rakyat (BPR) dan bank dengan kegiatan usaha terbatas yang memiliki modal di bawah Rp 100 miliar.

Sebagai kiblat perbankan, pengklasifikasian bank beibasis modal seperti. disebutkan diatas akan berimplikasi terhadap berubahnya peta bisnis perbankan di tanah air. Persaingan dalam pasar perbankan ke dépan akan menjadi lebih tajam dan kompetitif. Sehingga bank-bank dituntut untuk tidak hanya pandai dalam merawat kesehatannya namun juga harus cerdas dalam merumuskan core business-nya agar tidak tersingkir dalam peta baru perbankan tersebut. Jika sebuah bank memiliki kekuatan dalam pengelolaan bisnis ritel (retail banking), seyogianya bidang ini menjadi core business-nya. Sebaliknya jika sebuah 


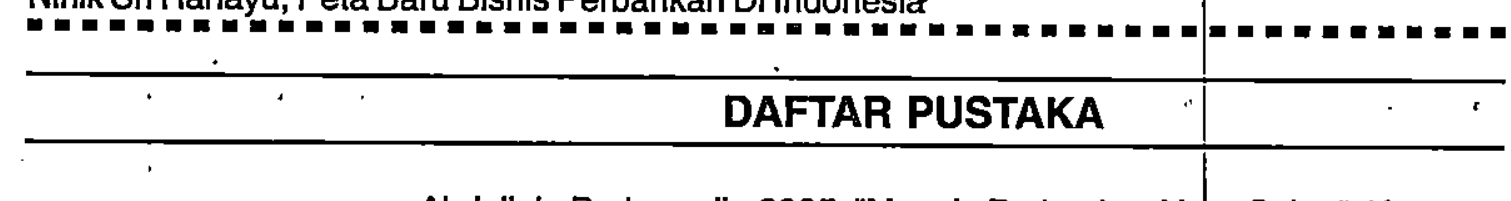

Abdullah, Burhanudin.2005. "Menuju Perbankan Yang Sehat", Kompas, 17 Jasnuari.

Ali, Masyhud.2004. "Asset Liability Management: Menyiasati Resiko Pasar dan Resiko Operasional dalam Perbankan", Elex Media Komputindo, Jakarta. www.bi.go.id

Budi Sarjito, Imam.2005. "Prospek Perbankan 2005", Avvailable at 21 Januari.

Kiryanto, Ryan. 2004. Implikasi Penataan Lanskap Perbankan, Kompas,

Ratnawati, Enny.2004. "Siapa Siap Jadi Bank Internasional?", Infobank, Edisi Februari, hal.22-23.

Sugiharto, Agus.2004. "Membangun Fundamental Perbankan". Available at www.bi.go.id

Kompas, www.bi.go.id

2004. "Mengapa Modal Minimum Bank Harus 100 Milyar?"

.2003. "Ársitektur Perbankan Indonesia: Suatu Kebutuhan dan Tantangan Perbankan Kedepan", available at www.bi.golid

able at www.bi.go.id

. 2004. "Mencari Struktur Perbankan Yang Ideal". AvailAvailable at www.bi.go.id

2004. " Mengapa Manajer Resiko Bank Perlu Disertifikasi?"

.2004. "Bagaimana Nasib Perbankan Kita Setelah Ditinggal IMF?", Available at www.bi.go.id

Silalahi, Tumpak. 2004. "Mengapa Perlu Arsitektur Perbankan Indonesia?", available at www.bi.go.id

Supriyanto, Eko. 2004. "Peta Baru Bisnis Bank", Infobank, Edisi Februari, hal.12-16.

Bank Indonesia.2005."Indikator Perbankan", available at www.bi.go.id 